\title{
TLR3 and TLR7 Cross-talk Induces Synergistic Response in the Chicken Peripheral Blood Mononuclear Cells
}

\author{
Deepthi Kappala ${ }^{1,2}$, Patel Nikunjkumar Prakashbhai ${ }^{1}$, \\ Yogendra Singh ${ }^{1}$ and Saravanan Ramakrishnan ${ }^{1^{*}}$
}

\author{
${ }^{1}$ Avian immunology laboratory, Immunology Section, ICAR - Indian Veterinary Research \\ Institute, Izatnagar, Bareilly, Uttar Pradesh, India \\ ${ }^{2}$ Department of veterinary microbiology, FVAS, RGSC, Banaras Hindu University, Mirzapur, \\ Uttar Pradesh, India
}

*Corresponding author

\section{A B S T R A C T}

\section{Keywords}

Chicken, Toll-like receptor, Poly I:C, R-848, TLR-TLR cross-talk, Cytokines, Nitric oxide

\section{Article Info}

Accepted:

10 January 2021

Available Online:

10 February 2021
Toll-like receptors (TLRs) are type of pattern recognition receptors (PRRs) greatly expressed on all immune cells. Activation of TLRs with their cognate ligand initiates the induction of innate immune responses with subsequent priming of adaptive immunity. Understanding the interaction between two different TLRs in terms of induced immune responses would help in using the TLR ligands as vaccine adjuvants. In the present study, effects of Poly I:C (TLR3 ligand) and/or R-848 (TLR7 ligand) were studied in chicken peripheral blood mononuclear cells (PBMCs). The PBMCs were isolated from White Leghorn chickens of around six weeks of age $(n=6)$ and stimulated with Poly I:C and R848 alone or in combination. The cells were harvested at different intervals $(3,6,12,24$ and $48 \mathrm{~h}$ ) post-stimulation and analyzed for the induction of different immune response genes by real-time PCR. The combination of PolyI:C and R- 848 synergistically induced the up-regulation of IL-1 $\beta$, IFN- $\beta$, IFN- $\gamma$, IL-4, IL-10 and iNOS transcripts as compared to the individual response in the chicken PBMCs. The results indicate that the combination of Poly I:C and R-848 would synergistically interact at cellular signaling level resulting in augmentation of pro-inflammatory, antiviral, Th1 and Th2 type of responses in the chicken.

\section{Introduction}

First line of defense against invasion of microbial pathogen is mediated by innate or natural immunity. Innate immune cells recognize a set of conserved molecular structures on microbes through germ line encoded receptors called pattern recognition receptors (PRRs). Toll-like receptors (TLRs) are type of PRRs and engagement of TLRs with their cognate ligands activate downstream signaling events that result in the induction of innate immune response by secreting inflammatory cytokines and type I interferons (IFNs). The secretion of inflammatory mediators not only activate innate immunity but also prime adaptive immune response which is responsible for the 
clearance of pathogen (Janeway and Medzhitov, 2002). Presently, ten TLRs were identified in human and thirteen TLRs in mice (El-Zayat et al., 2019). Lipopeptides are recognized by cell surface TLRs such as TLR1, 2 and 6; lipopolysachharide (LPS) by TLR4 and flagellin by TLR5. Endosomal TLRs such as TLR3 recognize double stranded (ds) viral RNA, TLR7 and 8 identify single stranded (ss) viral RNA and TLR9 recognize CpG ODN of DNA (Akira et al., 2006; Marshak-Rothstein, 2006). In chicken ten TLRs (TLR1A and TLR1B, TLR2A and TLR2B, TLR3, TLR4, TLR5, TLR7, TLR15 and TLR21) were reported (Paul et al., 2013).

Chicken TLR21 is functional homologue of human TLR9 which recognize $\mathrm{CpG}$ ODN motifs of DNA (Brownlie et al., 2009). TLR is composed of an extracellular domain containing leucine rich repeats responsible for ligand recognition and an intracellular toll/interleukin-1 (IL-1) receptor (TIR) like domain essential for signal transduction (Janssens and Beyaert, 2003; Kanzler et al., 2007). Except TLR3, binding of every single TLRs to their cognate ligands make use of Myeloid differentiation primary response gene88 (MyD88) as an adapter molecule for induction of signaling events in the cell. TLR3 uses TIR domain containing adaptor protein inducing IFN- $\beta$ (TRIF) and TLR4 utilizes both MyD88 and TRIF molecule (Honda et al., 2004; Kawai et al., 2004; Pandey and Agrawal, 2006).

During cell surface TLR activation, interleukin 1 receptor associated kinase (IRAK) family members IRAK1 and IRAK4 interacts with an adapter molecule MyD88 to form signaling complex myddosome (Lin et al., 2010). Within the signalosome or myddosome, IRAK4 activates IRAK1 which then autophosphorylate and release from MyD88 (Kollewe et al., 2004; Jiang et al., 2002). The released IRAK1 further associates with TNF receptor associated factor 6 (TRAF6) which promotes polyubiquitination and activation of transforming growth factor beta activated kinase 1 (TAK1) (Chen, 2012; Ajibade et al., 2013). TAK1 activates two different pathways; nuclear factor kappa B $(\mathrm{NF}-\kappa \mathrm{B})$ and mitogen activated protein kinase (MAPK) pathway.

In the former, TAK1 activates catalytic subunit of IKK (inhibitor of NF- $\kappa$ B (I $\kappa \mathrm{B})$ kinase) complex which further phosphorylate $\mathrm{NF}-\kappa \mathrm{B}$ inhibitory protein I $\kappa \mathrm{B} \alpha$. The phosphorylated $\mathrm{I} \kappa \mathrm{B} \alpha$ is degraded and unmasked from NF- $\kappa \mathrm{B}$ thus allows NF- $\kappa \mathrm{B}$ to tanslocate into the nucleus to activate proinflammatory genes. In addition, TAK 1 also activates MAPK family members; p38, extracellular signal-regulated protein kinase (ERK)1/2 and Jun $\mathrm{N}$ terminal kinase (JNK) which involve in induction of inflammatory response (Akira et al., 2006; Kawai and Akira, 2010).

TLR agonists were tried by many workers both as prophylactic agents as well as adjuvants in chicken. Polyinosinicpolycytidylic acid (PolyI:C; TLR3 agonist) as an adjuvant with avian influenza virus (AIV) increased the expression of IL-6, IL-12 and IFN- $\gamma$ in chickens (Liang et al., 2013). Prophylactic activity of PolyI:C was demonstrated with reduced viral shedding due to up-regulation of IFNs, IL-8 and IL-18 (Paul et al., 2012a).

In vitro stimulation of chicken embryo fibroblast with PolyI:C reduced replication of Marek's disease virus (Hu et al., 2016a). Recently, we reported the up-regulated expression of Th1 and Th2 immune response genes by R-848 (TLR7 agonist) in the chicken peripheral blood mononuclear cells (PBMCs) (Ramakrishnan et al., 2015), which was also confirmed by in vivo study (Annamalai et al., 2015). R-848 also showed potential adjuvant 
activity when used with inactivated Newcastle disease virus (NDV) vaccine and enhanced the protection level as observed by challenge with virulent Newcastle disease virus with no shedding of virus in the chicken (Sachan et al., 2015). Intramuscular and intranasal injection of $\mathrm{R}-848$ reduced the shedding of avian influenza virus in the chicken (Barjesteh et al., 2015). Simultaneous use of two different TLR ligands can cause interaction between their respective TLRs and lead to either additive, synergistic or antagonistic effect. Combination of TLR agonists can be tried to minimize the side effects, mimic the natural infection and to induce a more balanced or desired immune responses. Stimulation of porcine dendritic cells with PolyI:C and imiquimod (TLR7 agonist) along with the inactivated Porcine reproductive and respiratory syndrome (PRRS) virus antigen increased the expression of IFN- $\gamma$, IL-12, IL-6 and IL-10 mRNA level (Hu et al., 2016b).

Combination of TLR3 and TLR7 agonist boosted Th1 type of immunity in human and mice (Napolitani et al., 2005). Although the combinatorial effect of TLR3 and TLR7 is reported in human and mice, it is not reported in chicken. Therefore, our present study aimed to examine the combinatorial effect of TLR3 and TLR7 agonist in the chicken PBMCs.

\section{Materials and Methods}

\section{Experimental birds}

Specific pathogen free (SPF) embryonated eggs were procured from Venky's India Pvt. Ltd. Pune, India and hatched at Central Avian Research Institute (CARI), Izatnagar, India. Birds were maintained following standard management practices and provided with ad libitum autoclaved feed and water. The total experiment was approved by the Institute
Animal Ethical Committee (IAEC), Indian Veterinary Research Institute, Izatnagar, Bareilly, Uttar Pradesh, India 243122.

\section{TLR agonists}

Commercially available TLR3 agonist, PolyI:C and TLR7 agonist, R-848 were procured from InvivoGen, CA, USA and dissolved in sterile nuclease- and endotoxinfree water.

\section{Primers}

Published oligonucleotide primers specific to chicken genes viz., GAPDH, IL- $1 \beta$, IFN- $\beta$, IFN- $\gamma$, IL-4, IL-10 and inducible nitric oxide synthase (iNOS) were synthesized from M/S Integrated DNA Technologies, Iowa, USA and used in the study (Table 1).

\section{Chicken PBMCs isolation and stimulation}

Blood was collected in an anticoagulant containing vial (heparin, $20 \mathrm{IU} / \mathrm{ml}$ ) from six weeks old specific pathogen free (SPF) White Leghorn birds $(n=6)$. Blood was layered over equal volume of Ficoll Hypaque (Sigma, MO, USA) with specific gravity $1.077 \mathrm{~g} / \mathrm{ml}$, centrifuged at $500 \times \mathrm{g}$ for $45 \mathrm{~min}$. The interface containing the PBMCs was collected and washed twice in sterile phosphate buffered saline (PBS) ( $\mathrm{pH}$ 7.2) and resuspended in RPMI-1640 medium containing $2 \%$ fetal calf serum. Cell viability was determined by trypan blue dye exclusion method and cells were adjusted to a concentration of $1 \times 10^{6}$ cells $/ \mathrm{ml}$. PBMCs were stimulated with PolyI:C $(50 \mu \mathrm{g} / \mathrm{ml})$ and/or R-848 $(2 \mu \mathrm{g} / \mathrm{ml})$ as reported earlier (Karpala et al., 2008; Barjesteh et al., 2012; Bekeredjian-Ding et al., 2005). The cells were incubated at $40^{\circ} \mathrm{C}$ with $5 \% \mathrm{CO}_{2}$ and harvested at $0,3,6,12,24$ and $48 \mathrm{~h}$ post-stimulation for immune response genes analyses. 
Analysis of immune response genes by quantitative real-time PCR

\section{RNA extraction and cDNA synthesis}

The PBMCs were centrifuged for 2 min and the resulting pellet was resuspended in 750 $\mu \mathrm{L}_{\text {TRIzol }}^{\mathrm{TM}}$ (Invitrogen, CA, USA). The resulting mixture was extracted with chloroform and precipitated with isopropanol. The RNA pellet was briefly washed with $75 \%$ ethanol and resuspended in nuclease free water (Invitrogen, CA, USA). Upon isolation of RNA, cDNA synthesis was carried out using random hexamer primers (Fermentas, MD, USA) and Revertaid ${ }^{\mathrm{TM}}$ First Strand cDNA Synthesis Kit (Thermo Scientific, USA).

\section{Real-time PCR quantification}

Expression levels of mRNA of IL-1 $\beta$, IFN- $\beta$, IFN- $\gamma$, IL-4, IL-10 and iNOS were analyzed by real-time PCR using the QuantiFast SYBR Green qPCR kit (Qiagen, CA, USA) on CFX96 real time system (Bio-Rad, CA, USA) using published gene specific primers. GAPDH was used as the reference gene. Real-time PCR was carried out in a total volume of $20 \mu \mathrm{L}$ consisting of $2 \mu \mathrm{L}$ cDNA, $10 \mu \mathrm{L}$ of QuantiFast SYBR Green Master Mix (Qiagen, CA, USA), and primers $0.5 \mu \mathrm{L}$ each. Real time PCR was carried out with the following programme: 1 cycle at $95{ }^{\circ} \mathrm{C}$ for 5 min, followed by 40 cycles of $94{ }^{\circ} \mathrm{C}$ for $30 \mathrm{~s}$, $60{ }^{\circ} \mathrm{C}$ for $45 \mathrm{~s}, 70{ }^{\circ} \mathrm{C}$ for $45 \mathrm{~s}$ and 1 cycle of 94 ${ }^{\circ} \mathrm{C}$ for $30 \mathrm{~s}$. The final step was to obtain a melt curve for the PCR products to determine the specificity of the amplicons. Each sample was run in triplicate on the same plate. Expression levels of the above mentioned different genes were calculated relative to the expression of the GAPDH gene and expressed as n-fold increase or decrease relative to the control samples (Pfaffl, 2001).

\section{Statistical analysis}

GraphPad Prism 7.0 was used for the statistical analyses. Two way analysis of variance (ANOVA) was performed to determine the effect of agonists and their interactions. Results are expressed as Mean \pm SEM.

\section{Results and Discussion}

Effect of polyI:C and/or R-848 on proinflammatory gene expression in the chicken PBMCs

Pro-inflammatory cytokines play a pivotal role in both innate and adaptive immunity and as a crucial mediator of inflammatory response. IL-1 $\beta$ also possesses direct antiviral activity by decreasing the viral load in the respiratory mucosa of the infectious laryngotracheitis virus infected chicken (Thapa et al., 2015). In our study, PolyI:C induced the expression of IL- $1 \beta$ mRNA at all the time intervals in the chicken PBMCs (Figure 1). Further, the expression level of IL$1 \beta$ transcript (38.575 \pm 12.298$)$ was higher at 3 $\mathrm{h}$ post-stimulation with Poly I:C in comparison to other intervals studied.

The level of IL-1 $\beta$ transcript gradually decreased at the later time period. Similarly R-848 induced a peak IL-1 $\beta(36.186 \pm 12.271)$ expression at $3 \mathrm{~h}$ post-stimulation in the chicken PBMCs than any other interval studied (Figure 1). Further the combination of Poly I:C and R-848 synergistically $(122.853 \pm 36.719)$ up-regulated the IL-1 $\beta$ transcripts at $3 \mathrm{~h}$ post-stimulation as compared to the additive effect of either of the agonist in the chicken PBMCs (Figure 1). Our study is in agreement with the earlier reports where Poly I:C amplified the expression of IL-1 $\beta$ mRNA in the microglial cells (Ifuku et al., 2014). Similarly, R-848 elevated the IL-1 $\beta$ mRNA expression in 
chicken splenocytes and chicken TLR7+ HD11 cell line (Philbin et al., 2005). An increase in biological active IL- $1 \beta$ transcript after Poly I:C plus R-848 stimulation in dendritic cells (Napolitani et al., 2005) supports the present findings.

\section{Effect of poly I:C and/or R-848 on antiviral gene expression in the chicken PBMCs}

Macrophages, monocytes, $\mathrm{T}$ cells and $\mathrm{B}$ cells are predominant producer of type I IFNs which in turn activate IFN stimulatory genes (Seo and Hahm, 2010). IFN- $\alpha$ and IFN- $\beta$ have well defined antiviral activity and the type I IFNs act in cis to induce dendritic cell maturation that subsequently enhance the adaptive immunity (Rahman and Eo, 2012). In our study, Poly I:C induced IFN- $\beta$ expression in chicken PBMCs with a peak increase at $6 \mathrm{~h}$ (3.322 \pm 1.487$)$ poststimulation (Figure 2). The expression level of IFN- $\beta$ was greatest at $48 \mathrm{~h}(4.058 \pm 1.949)$ post-stimulation with R-848 (Figure 2). Further, the combination of Poly I:C and R848 stimulation synergistically enhanced IFN$\beta$ transcript (19.017 \pm 11.421$)$ at $48 \mathrm{~h}$ interval as compared to the additive effect of either of the agonist alone (Figure 2).

In consistent to our study when chicken cells stimulated with Poly I:C, induced strong TRIF mediated IFN- $\beta$ response (Rothfuchs $e t$ al., 2001). Oral administration of synthetic TLR7 agonist S-28828 induced type I IFNs in chicken splenocytes (Karaca et al., 1996). Similarly, R-848 also induced IFN- $\alpha$ and IFN- $\beta$ in human peripheral lymphocytes (Lee et al., 2003). Stimulation of dendritic cells with dual agonists, Poly I:C and R-848 enhanced IFN- $\alpha$, IFN- $\beta$ and IL-12 cytokines which confirms the result of our study (Pearson et al., 2018).

Table.1

\begin{tabular}{|c|c|c|c|}
\hline $\begin{array}{l}\text { Target } \\
\text { Gene }\end{array}$ & Primer sequence (5'-3') & $\begin{array}{l}\text { Product } \\
\text { size (bp) }\end{array}$ & Reference \\
\hline GAPDH & $\begin{array}{l}\text { F: AGCACCCGCATCAAAGG } \\
\text { R: CATCATCCCAGCGTCCA }\end{array}$ & 283 & Kuo et al., 2017 \\
\hline IL-1及 & $\begin{array}{l}\text { F: GGATTCTGAGCACACCACAGT } \\
\text { R: TCTGGTTGATGTCGAAGATGTC }\end{array}$ & 272 & $\begin{array}{l}\text { Ramakrishnan et al., } \\
2015\end{array}$ \\
\hline IFN- $\beta$ & $\begin{array}{l}\text { F: GCTCACCTCAGCATCAACAA } \\
\text { R: GGGTGTTGAGACGTTTGGAT }\end{array}$ & 187 & $\begin{array}{l}\text { Ramakrishnan et al., } \\
2015\end{array}$ \\
\hline IFN- $\gamma$ & $\begin{array}{l}\text { F: TGAGCCAGATTGTTTCGATG } \\
\text { R: CTTGGCCAGGTCCATGATA }\end{array}$ & 152 & $\begin{array}{l}\text { Ramakrishnan et al., } \\
2015\end{array}$ \\
\hline IL-4 & $\begin{array}{l}\text { F: GTGCCCACGCTGTGCTTAC } \\
\text { R: AGGAAACCTCTCCCTGGATGTC }\end{array}$ & 82 & Huang et al., 2019 \\
\hline IL-10 & $\begin{array}{l}\text { F: CGCTGTCACCGCTTCTTCA } \\
\text { R: TCCCGTTCTCATCCATCTTCTC }\end{array}$ & 88 & Zhang et al., 2019 \\
\hline iNOS & $\begin{array}{l}\text { F: TGGGTGGAAGCCGAAATA } \\
\text { R: GTACCAGCCGTTGAAAGGAC }\end{array}$ & 241 & Zhang et al., 2019 \\
\hline
\end{tabular}


Fig.1 Relative expression of IL-1 $\beta$ transcript in chicken peripheral blood mononuclear cells (PBMCs) stimulated with Poly I:C $(50 \mu \mathrm{g} / \mathrm{ml})$ and/or R-848 $(2 \mu \mathrm{g} / \mathrm{ml})$ over a period of $48 \mathrm{~h}$. Bars with different uppercase indicate significant effect of TLR agonist at a time point

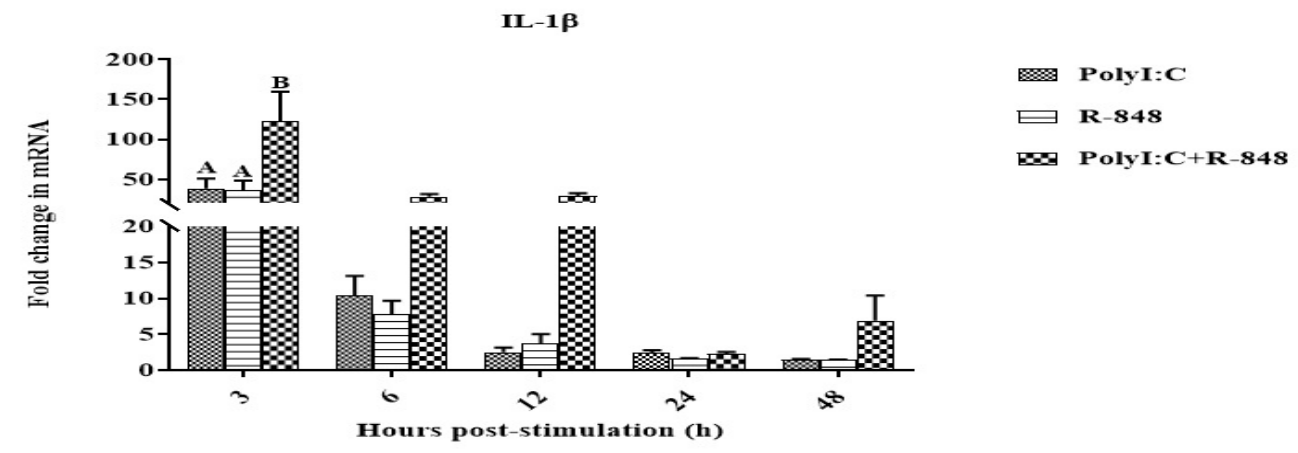

Fig.2 Relative expression of IFN- $\beta$ transcript in chicken peripheral blood mononuclear cells PBMCs) stimulated with Poly I:C $(50 \mu \mathrm{g} / \mathrm{ml})$ and/or R-848 $(2 \mu \mathrm{g} / \mathrm{ml})$ over a period of $48 \mathrm{~h}$. Bars with different uppercase indicate significant effect of TLR agonist at a time point

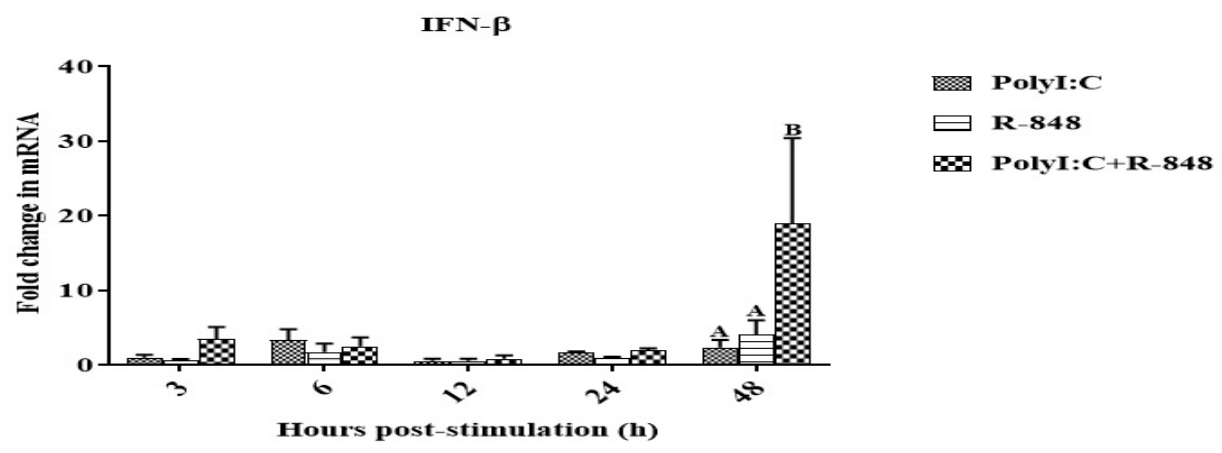

Fig.3 Relative expression of IFN- $\gamma$ transcript in chicken peripheral blood mononuclear cells (PBMCs) stimulated with Poly I:C $(50 \mu \mathrm{g} / \mathrm{ml})$ and/or R-848 $(2 \mu \mathrm{g} / \mathrm{ml})$ over a period of $48 \mathrm{~h}$. Bars with different uppercase indicate significant effect of TLR agonist at a time point

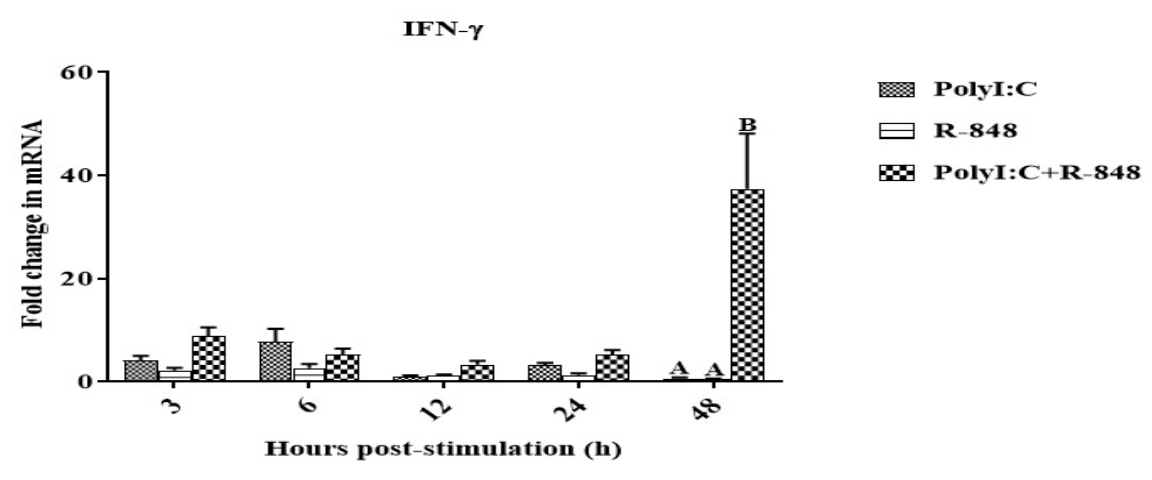


Fig.4 Relative expression of IL-4 transcript in chicken peripheral blood mononuclear cells (PBMCs) stimulated with Poly I:C $(50 \mu \mathrm{g} / \mathrm{ml})$ and/or R-848 $(2 \mu \mathrm{g} / \mathrm{ml})$ over a period of $48 \mathrm{~h}$. Bars with different uppercase indicate significant effect of TLR agonist at a time point

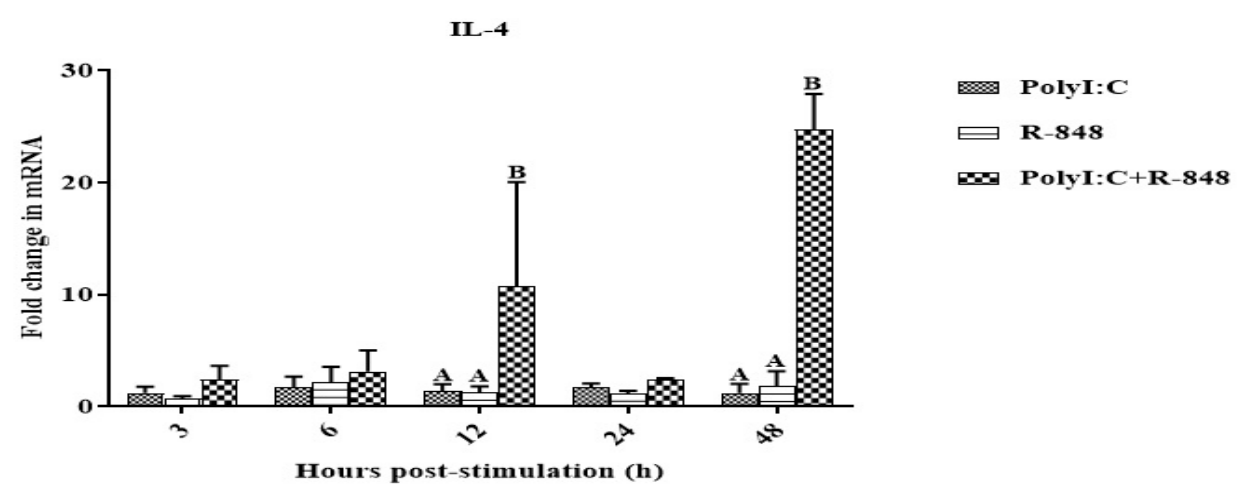

Fig.5 Relative expression of IL-10 transcript in chicken peripheral blood mononuclear cells (PBMCs) stimulated with Poly I:C $(50 \mu \mathrm{g} / \mathrm{ml})$ and/or R-848 $(2 \mu \mathrm{g} / \mathrm{ml})$ over a period of $48 \mathrm{~h}$. Bars with different uppercase indicate significant effect of TLR agonist at a time point

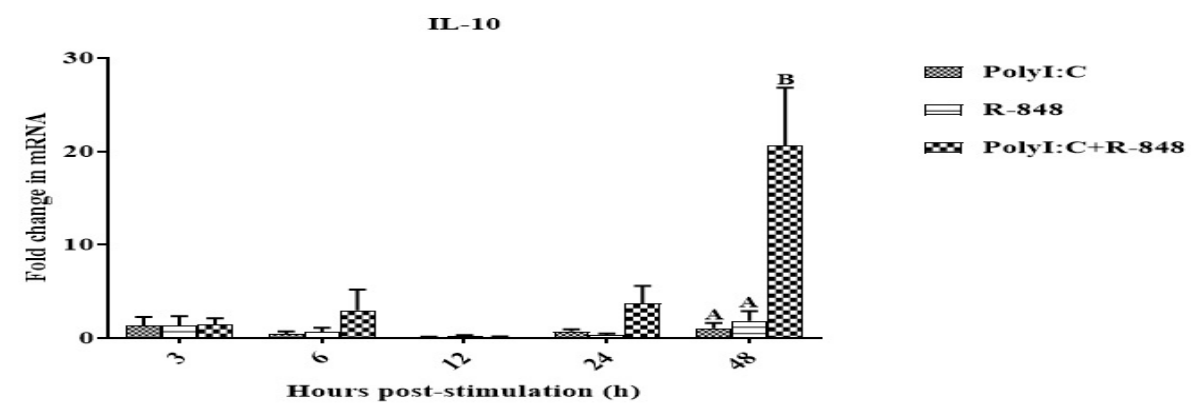

Fig.6 Relative expression of iNOS transcript in chicken peripheral blood mononuclear cells (PBMCs) stimulated with Poly I:C $(50 \mu \mathrm{g} / \mathrm{ml})$ and/or R-848 $(2 \mu \mathrm{g} / \mathrm{ml})$ over a period of $48 \mathrm{~h}$. Bars with different uppercase indicate significant effect of TLR agonist at a time point

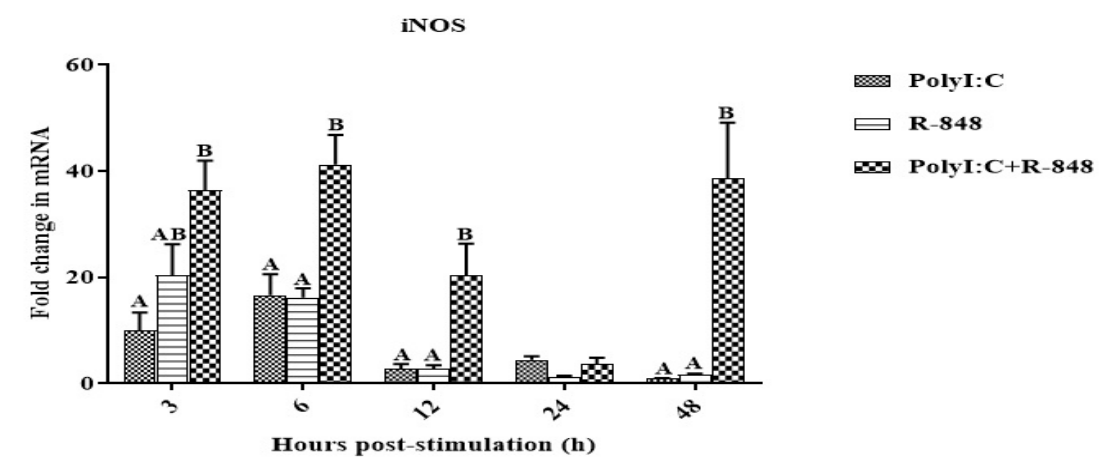


Effect of polyI:C and/or R-848 on Th1 cytokine gene expression in chicken PBMCs

IFN- $\gamma$ is a hallmark of cellular immune response (Boyoglu-Barnum et al., 2014; Miceli and Parnes, 1991; Koretzky, 2010). It plays an essential role in both innate and adaptive immunity (Samuel, 2001). IFN- $\gamma$ also possesses antiviral activity by inducing $\mathrm{CD} 8+\mathrm{T}$ cells, natural killer cells and interferon inducible genes (Samuel, 2001). In our current study, Poly I:C induced the expression of IFN- $\gamma$ transcript at 3, 6, 12 and $24 \mathrm{~h}$ post-stimulation with peak increase at 6 h (7.680 \pm 2.561$)$ interval (Figure 3). Similarly, R-848 induced the IFN- $\gamma$ transcript at 3, 6, 12 and $24 \mathrm{~h}$ post-stimulation in the chicken PBMCs. The combination of Poly I:C and R848 showed synergistic effect on IFN- $\gamma$ transcript at $48 \mathrm{~h}$ post-stimulation in chicken PBMCs as compared to the additive effect of either of the agonist alone (Figure 3). In accordance to our result, Poly I:C treatment increased the expression of TLR3 and IFN- $\gamma$ transcripts in bursal cells (Paul et al., 2012b). In human PBMCs, Poly I:C and R-848 strongly induced the IFN- $\gamma$ transcript and supported Th1 differentiation (Re and Strominger, 2004; Ito et al., 2002; Huang et al., 2006). Further, stimulation of porcine peripheral blood monocyte derived dendritic cells with dual TLR3 and TLR7 ligands synergistically enhanced mRNA and protein levels of Th1 type cytokines IFN- $\gamma$ and IL-12 through TRIF/MyD88 NF- $\mathrm{BB}$ signaling pathway.

Effect of poly I:C and/or R-848 on Th2 cytokine gene expression in chicken PBMCs

Th2 cytokines such as IL-4 and IL-10 is indicative of humoral and mucosal immune response (Boyoglu-Barnum, 2014; Miceli et al., 1991; Koretzky, 2010). IL-4 and IL-10 is predominantly produced by CD4+ Th2 cells and subdues the excessive response produced by Th1 and CD8+ T cells that are responsible for immunopathology associated during infection (Gazzinelli et al., 1996; Wilson et al., 2005). In our present study, PolyI:C and $\mathrm{R}-848$ induced IL-4 mRNA expression in chicken PBMCs at all the time intervals studied. PolyI:C plus R-848 synergistically enhanced the expression of IL-4 transcript at $12 \mathrm{~h}(10.782 \pm 9.271)$ and $48 \mathrm{~h}(24.742 \pm 3.189)$ post-stimulation as compared to the additive effect of either of the agonist alone (Figure 4). Further synergistic response was appreciated in the expression of IL-10 mRNA after PolyI:C plus R-848 stimulation in chicken PBMCs (Figure 5). In agreement with our study, treatment of human lymphocytes increased the expression of IL-4 mRNA through NF-kB pathway (Kehoe et al., 2001). $\mathrm{R}-848$ induced higher levels of IFN- $\gamma$ and IL4 in mice splenocytes (Wang et al., 2013), which also supports our findings. Stimulation of bursal cells with PolyI:C induced IL-10 (Paul et al., 2012b) which is important for down-regulating the deleterious effects associated with the diseases. The combination of TLR3 and TLR7 ligands synergistically enhanced Th2 cytokines IL-6 and IL-10 in human dendritic cells (Hu et al., 2016b) which supports the finding of our results.

\section{Effect of polyI:C and/or R-848 on iNOS gene expression in chicken PBMCs}

Nitric oxide plays a major role in host defense against viral infections and tumors (Eisenstein, 2001). In our present study, Poly I:C induced the iNOS transcript at all the time interval studied with a peak increase at $6 \mathrm{~h}$ (16.628 \pm 3.968$)$ post-stimulation. Significant $(\mathrm{P}<0.05)$ increase in the level of iNOS mRNA was appreciated in chicken PBMCs at $3 \mathrm{~h}$ post-stimulation with $\mathrm{R}-848$ as compared to Poly I:C. The combination of Poly I:C and R848 significantly $(\mathrm{P}<0.05)$ enhanced the 
expression of iNOS transcript at 3, 6, 12 and $48 \mathrm{~h}$ post-stimulation as compared to the individual agonists. However, the combination synergistically enhanced the iNOS mRNA at $48 \mathrm{~h}$ post-stimulation as compared to additive effect of either of the agonists (Figure 6). In consistent to our results, stimulation of RAW 264.7 cells with Poly I:C increased the expression of iNOS transcript and production of nitric oxide (Heitmeier et al., 1998) which was able to inhibit the replication of virus in vitro (Djeraba et al.,2000). Similarly, exposure to R-848 induced the up-regulation of iNOS mRNA in chicken macrophage like cell line (Peroval et al., 2013).

In conclusion, co-stimulation of chicken PBMCs with Poly I:C and R-848 showed a synergistic up-regulation of IL- $1 \beta$, IFN- $\beta$, IFN- $\gamma$, IL-4, IL-10 and iNOS transcripts than either of the agonists alone. This suggests that the combination of Poly I:C and R-848 can augment the pro-inflammatory, antiviral, Th1 and Th2 type immune responses in the chicken PBMCs. Our findings may pave way to study the adjuvant potential of Poly I:C plus R-848 with common poultry vaccines.

\section{Acknowledgements}

The authors thank the Director, Indian Veterinary Research Institute for providing the facilities to carry out the work. This work was supported by a research grant from the Department of Biotechnology, Ministry of Science and Technology, Government of India.

\section{References}

Ajibade, A.A., Wang, H.Y., and Wang, R.F. 2013. Cell type-specific function of TAK1 in innate immune signaling. Trends in immunology. 34 (7): 307-316.

Akira, S., Uematsu, S., and Takeuchi, O.
2006. Pathogen recognition and innate immunity. Cell. 124 (4): 783-801.

Annamalai, A., Ramakrishnan, S., Sachan, S., Sharma, B.K., Kumar, B.A., Kumar, V., Badasara, S.K., Kumar, A., Saravanan, B.C., and Krishnaswamy, N. 2015. Administration of TLR7 agonist, resiquimod, in different types of chicken induces a mixed Th1 and Th2 response in the peripheral blood mononuclear cells. Research in veterinary science. 100: 105-108.

Barjesteh, N., Paolucci, S., Pei, Y., and Sharif, S. 2012. Toll-like receptor ligands induce the expression of interferon-gamma and interleukin-17 in chicken CD4+ $\mathrm{T}$ cells. BMC research notes. 5 (1): 616 .

Barjesteh, N., Shojadoost, B., Brisbin, J.T., Emam, M., Hodgins, D.C., Nagy, E., and Sharif, S. 2015. Reduction of avian influenza virus shedding by administration of Toll-like receptor ligands to chickens. Vaccine. 33 (38): 4843-4849.

Bekeredjian-Ding, I.B., Wagner, M., Hornung, V., Giese, T., Schnurr, M., Endres, S., and Hartmann, G. 2005. Plasmacytoid dendritic cells control TLR7 sensitivity of naive B cells via type I IFN. The journal of immunology. 174 (7): 4043-4050.

Boyoglu-Barnum, S., Chirkova, T., Todd, S.O., Barnum, T.R., Gaston, K.A., Jorquera, P., Haynes, L.M., Tripp, R.A., Moore, M.L., and Anderson, L.J. 2014. Prophylaxis with a respiratory syncytial virus (RSV) anti-G protein monoclonal antibody shifts the adaptive immune response to RSV rA2-line19F infection from Th2 to Th1 in BALB/c mice. Journal of virology. 88 (18): 10569 10583.

Brownlie, R., Zhu, J., Allan, B., Mutwiri, G.K., Babiuk, L.A., Potter, A., and Griebel, P. 2009. Chicken TLR21 acts 
as a functional homologue to mammalian TLR9 in the recognition of $\mathrm{CpG}$ oligodeoxynucleotides. Molecular immunology. 46 (15): 3163-3170.

Chen, Z.J. 2012. Ubiquitination in signaling to and activation of IKK. Immunological reviews. 246 (1): 95106.

Djeraba, A., Bernardet, N., Dambrine, G., and Quéré, P. 2000. Nitric oxide inhibits Marek's disease virus replication but is not the single decisive factor in interferon- $\gamma$-mediated viral inhibition. Virology. 277 (1): 58-65.

Eisenstein, T.K. 2001. Implications of Salmonella-induced nitric oxide (NO) for host defense and vaccines: NO, an antimicrobial, antitumor, immunosuppressive and immunoregulatory molecule. Microbes and infection. 3 (14-15): 1223-1231.

El-Zayat, S.R., Sibaii, H. \& Mannaa, F.A. Toll-like receptors activation, signaling, and targeting: an overview. Bull Natl

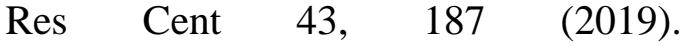
https://doi.org/10.1186/s42269-0190227-2

Gazzinelli, R.T., Wysocka, M., Hieny, S., Scharton-Kersten, T., Cheever, A., Kühn, R., Müller, W., Trinchieri, G., and Sher, A. 1996. In the absence of endogenous IL-10, mice acutely infected with Toxoplasma gondii succumb to a lethal immune response dependent on CD4+ $\mathrm{T}$ cells and accompanied by overproduction of IL12, IFN-gamma and TNF-alpha. The Journal of immunology. 157 (2): 798805.

Heitmeier, M.R., Scarim, A.L., and Corbett, J.A. 1998. Double-stranded RNAinduced inducible nitric-oxide synthase expression and interleukin-1 release by murine macrophages requires $\mathrm{NF}-\kappa \mathrm{B}$ activation. Journal of biological chemistry. 273 (24): 15301-15307.
Honda, K., Yanai, H., Mizutani, T., Negishi, H., Shimada, N., Suzuki, N., Ohba, Y., Takaoka, A., Yeh, W.C., and Taniguchi, T. 2004. Role of a transductionaltranscriptional processor complex involving MyD88 and IRF-7 in toll-like receptor signaling. Proceedings of the national academy of sciences. 101 (43): 15416-15421.

Hu, X., Zou, H., Qin, A., Qian, K., Shao, H., and Ye, J. 2016a. Activation of Tolllike receptor 3 inhibits Marek's disease virus infection in chicken embryo fibroblast cells. Archives of virology. 161 (3): 521-528.

Hu, Y., Cong, X., Chen, L., Qi, J., Wu, X., Zhou, M., Yoo, D., Li, F., Sun, W., Wu, J., and Zhao, X. 2016b. Synergy of TLR3 and 7 ligands significantly enhances function of DCs to present inactivated PRRSV antigen through TRIF/MyD88-NF- $\kappa$ B signaling pathway. Scientific reports. 6: 23977.

Huang, C.C., Duffy, K.E., San Mateo, L.R., Amegadzie, B.Y., Sarisky, R.T., and Mbow, M.L. 2006. A pathway analysis of poly (I:C)-induced global gene expression change in human peripheral blood mononuclear cells. Physiological genomics. 26 (2): 125-133.

Huang, H., Jiao, X., Xu, Y., Han, Q., Jiao, W., Liu, Y., Li, S. and Teng, X., 2019. Dietary selenium supplementation alleviates immune toxicity in the hearts of chickens with lead-added drinking water. Avian Pathology, 48(3), pp.230237.

Huo, S., Zuo, Y., Li, N., Li, X., Zhang, Y., Wang, L., Liu, H., Zhang, J., Cui, D., He, P., and Xu, J. 2016. Chicken IL-7 as a potent adjuvant enhances IBDV VP2 DNA vaccine immunogenicity and protective efficacy. Veterinary microbiology. 193: 145-155.

Ifuku, M., Hossain, S.M., Noda, M., and Katafuchi, T. 2014. Induction of 
interleukin- $1 \beta$ by activated microglia is a prerequisite for immunologically induced fatigue. European Journal of Neuroscience, 40 (8): 3253-3263.

Ito, T., Amakawa, R., Kaisho, T., Hemmi, H., Tajima, K., Uehira, K., Ozaki, Y., Tomizawa, H., Akira, S., and Fukuhara, S. 2002. Interferon- $\alpha$ and interleukin-12 are induced differentially by Toll-like receptor 7 ligands in human blood dendritic cell subsets. The Journal of experimental medicine. 195 (11): 15071512.

Janeway Jr, C.A., and Medzhitov, R. 2002. Innate immune recognition. Annual review of immunology. 20 (1): 197-216.

Janssens, S., and Beyaert, R. 2003. Role of Toll-like receptors in pathogen recognition. Clinical microbiology reviews. 16 (4): 637-646.

Jiang, Z., Ninomiya-Tsuji, J., Qian, Y., Matsumoto, K., and Li, X. 2002. Interleukin-1 (IL-1) receptor-associated kinase-dependent IL-1-induced signaling complexes phosphorylate TAK1 and TAB2 at the plasma membrane and activate TAK1 in the cytosol. Molecular and cellular biology. 22 (20): 7158-7167.

Kanzler, H., Barrat, F.J., Hessel, E.M., and Coffman, R.L. 2007. Therapeutic targeting of innate immunity with Tolllike receptor agonists and antagonists. Nature medicine. 13 (5): 552-559.

Karaca, K., Sharma, J.M., Tomai, M.A., and Miller, R.L. 1996. In vivo and in vitro interferon induction in chickens by $\mathrm{S}$ 28828, an imidazoquinolinamine immunoenhancer. Journal of interferon and cytokine research. 16 (4): 327-332.

Karpala, A.J., Lowenthal, J.W., and Bean, A.G. 2008. Activation of the TLR3 pathway regulates IFN $\beta$ production in chickens. Developmental and comparative immunology. 32 (4): 435444.
Kawai, T., and Akira, S. 2010. The role of pattern-recognition receptors in innate immunity: update on Toll-like receptors. Nature immunology. 11 (5): 373.

Kawai, T., Sato, S., Ishii, K.J., Coban, C., Hemmi, H., Yamamoto, M., Terai, K. Matsuda, M., Inoue, J., Uematsu, S., Takeuchi, O., and Akira, S. 2004. Interferon- $\alpha$ induction through Toll-like receptors involves a direct interaction of IRF7 with MyD88 and TRAF6. Nature immunology. 5 (10): 1061-1068.

Kehoe, K.E., Brown, M.A., and Imani, F. 2001. Double-stranded RNA regulates IL-4 expression. The journal of immunology. 167 (5): 2496-2501.

Kollewe, C., Mackensen, A.C., Neumann, D., Knop, J., Cao, P., Li, S., Wesche, H., and Martin, M.U. 2004. Sequential autophosphorylation steps in the interleukin-1 receptor-associated kinase-1 regulate its availability as an adapter in interleukin-1 signaling. Journal of Biological Chemistry. 279 (7): 5227-5236.

Koretzky, G.A. 2010. Multiple roles of CD4 and $\mathrm{CD} 8$ in $\mathrm{T}$ cell activation. The Journal of Immunology. 185 (5): 26432644.

Kuo, S.M., Chen, C.J., Chang, S.C., Liu, T.J., Chen, Y.H., Huang, S.Y. and Shih, S.R., 2017. Inhibition of avian influenza A virus replication in human cells by host restriction factor TUFM is correlated with autophagy. MBio, 8(3).

Lee, J., Chuang, T.H., Redecke, V., She, L., Pitha, P.M., Carson, D.A., Raz, E., and Cottam, H.B. 2003. Molecular basis for the immunostimulatory activity of guanine nucleoside analogs: activation of Toll-like receptor 7. Proceedings of the national academy of sciences, 100 (11): 6646-6651.

Liang, J., Fu, J., Kang, H., Lin, J., Yu, Q., and Yang, Q. 2013. Comparison of 3 kinds 
of Toll-like receptor ligands for inactivated avian $\mathrm{H} 5 \mathrm{~N} 1$ influenza virus intranasal immunization in chicken. Poultry science. 92 (10): 2651-2660.

Lin, S.C., Lo, Y.C., and Wu, H. 2010. Helical assembly in the MyD88-IRAK4IRAK2 complex in TLR/IL-1R signalling. Nature. 465 (7300): 885-890.

Liu, H., Zhang, M., Han, H., Yuan, J. and Li, Z., 2010. Comparison of the expression of cytokine genes in the bursal tissues of the chickens following challenge with infectious bursal disease viruses of varying virulence. Virology Journal, 7(1), pp.1-9.

Marshak-Rothstein, A. 2006. Toll-like receptors in systemic autoimmune disease. Nature reviews immunology. 6 (11): 823-835.

Miceli, M.C., and Parnes, J.R. 1991. The roles of CD4 and CD8 in T cell activation. Seminars in immunology. 3 (3): 133 141.

Napolitani, G., Rinaldi, A., Bertoni, F., Sallusto, F., and Lanzavecchia, A. 2005. Selected Toll-like receptor agonist combinations synergistically trigger a $\mathrm{T}$ helper type 1-polarizing program in dendritic cells. Nature immunology. 6 (8): 769-776.

Pandey, S., and Agrawal, D.K. 2006. Immunobiology of Toll-like receptors: emerging trends. Immunology and cell biology. 84: 333-341.

Paul, M.S., Brisbin, J.T., Abdul-Careem, M.F., and Sharif, S. 2013. Immunostimulatory properties of Tolllike receptor ligands in chickens. Veterinary immunology and immunopathology. 152 (3-4): 191-199.

Paul, M.S., Mallick, A.I., Read, L.R., Villanueva, A.I., Parvizi, P., AbdulCareem, M.F., Nagy, É. and Sharif, S. 2012a. Prophylactic treatment with Toll-like receptor ligands enhances host immunity to avian influenza virus in chickens. Vaccine. 30 (30): 4524-4531.

Paul, M.S., Paolucci, S., Read, L.R., and Sharif, S. 2012b. Characterization of responses elicited by Toll-like receptor agonists in cells of the bursa of Fabricius in chickens. Veterinary immunology and immunopathology. 149 (3-4): 237-244.

Pearson, F.E., Chang, K., Minoda, Y., Rojas, I.M.L., Haigh, O.L., Daraj, G., Tullett, K.M., and Radford, K.J. 2018. Activation of human CD141+ and CD1c+ dendritic cells in vivo with combined TLR3 and TLR7/8 ligation. Immunology and cell biology. 96 (4): 390-400.

Peroval, M.Y., Boyd, A.C., Young, J.R., and Smith, A.L. 2013. A critical role for MAPK signalling pathways in the transcriptional regulation of toll like receptors. PloS one. 8 (2): e51243.

Pfaffl, M.W. 2001. A new mathematical model for relative quantification in realtime RT-PCR. Nucleic acids research. 29 (9): e45-e45.

Philbin, V.J., Iqbal, M., Boyd, Y., Goodchild, M.J., Beal, R.K., Bumstead, N., Young, J. and Smith, A.L. 2005. Identification and characterization of a functional, alternatively spliced Toll-like receptor 7 (TLR7) and genomic disruption of TLR8 in chickens. Immunology. 114 (4): 507-521.

Rahman, M.M., and Eo, S.K. 2012. Prospects and challenges of using chicken cytokines in disease prevention. Vaccine. 30 (50): 7165-7173.

Ramakrishnan, S., Annamalai, A., Sachan, S., Kumar, A., Sharma, B.K., Govindaraj, E., Chellappa, M.M., Dey, S., and Krishnaswamy, N. 2015. Synergy of lipopolysaccharide and resiquimod on type I interferon, pro-inflammatory cytokine, Th1 and Th2 response in chicken peripheral blood mononuclear cells. Molecular immunology. 64 (1): 
177-182.

Re, F. and Strominger, J.L. 2004. IL-10 released by concomitant TLR2 stimulation blocks the induction of a subset of Th1 cytokines that are specifically induced by TLR4 or TLR3 in human dendritic cells. The Journal of immunology. 173 (12): 7548-7555.

Rothfuchs, A.G., Gigliotti, D., Palmblad, K., Andersson, U., Wigzell, H., and Rottenberg, M.E. 2001. IFN- $\alpha \beta$ dependent, IFN- $\gamma$ secretion by bone marrow-derived macrophages controls an intracellular bacterial infection. The journal of immunology. 167 (11): 64536461.

Sachan, S., Ramakrishnan, S., Annamalai, A., Sharma, B.K., Malik, H., Saravanan, B.C., Jain, L., Saxena, M., Kumar, A., and Krishnaswamy, N. 2015. Adjuvant potential of resiquimod with inactivated Newcastle disease vaccine and its mechanism of action in chicken. Vaccine. 33 (36): 4526-4532.

Samuel, C.E. 2001. Antiviral actions of interferons. Clinical microbiology reviews. 14 (4): 778-809.

Seo, Y.J., and Hahm, B. 2010. Type I interferon modulates the battle of host immune system against viruses. Advances in applied microbiology. 73: 83-101.
Thapa, S., Cader, M.S.A., Murugananthan, K., Nagy, E., Sharif, S., Czub, M., and Abdul-Careem, M.F. 2015. In ovo delivery of $\mathrm{CpG}$ DNA reduces avian infectious laryngotracheitis virus induced mortality and morbidity. Viruses. 7 (4): 1832-1852.

Wang, X., Dong, L., Ni, H., Zhou, S., Xu, Z., Hoellwarth, J.S., Chen, X., Zhang, R., Chen, Q., Liu, F., and Wang, J. 2013. Combined TLR7/8 and TLR9 ligands potentiate the activity of a Schistosoma japonicum DNA vaccine. PLOS neglected tropical diseases. 7 (4): e2164.

Wilson, M.S., Taylor, M.D., Balic, A., Finney, C.A., Lamb, J.R., and Maizels, R.M. 2005. Suppression of allergic airway inflammation by helminthinduced regulatory $\mathrm{T}$ cells. The journal of experimental medicine. 202 (9): 1199-1212.

Zhang, B., Gan, L., Shahid, M.S., Lv, Z., Fan, H., Liu, D. and Guo, Y., 2019. In vivo and in vitro protective effect of arginine against intestinal inflammatory response induced by Clostridium perfringens in broiler chickens. Journal of animal science and biotechnology, 10(1), pp.114.

\section{How to cite this article:}

Deepthi Kappala, Patel Nikunjkumar Prakashbhai, Yogendra Singh and Saravanan Ramakrishnan. 2021. TLR3 and TLR7 Cross-talk Induces Synergistic Response in the Chicken Peripheral Blood Mononuclear Cells. Int.J.Curr.Microbiol.App.Sci. 10(02): 1043-1055. doi: https://doi.org/10.20546/ijcmas.2021.1002.123 